(C) Horn J., 2021

DOI 10.18019/1028-4427-2021-27-4-450-452

\title{
Treatment of idiopathic increased femoral anteversion in children and adolescents - a perspective
}

\author{
J. Horn ${ }^{1,2}$ \\ ${ }^{1}$ University of Oslo, Norway, \\ ${ }^{2}$ Oslo University Hospital, Oslo, Norway
}

\begin{abstract}
Rotational problems of the lower extremities affect a vast number of infants and children, whereas increased femoral anteversion (inward rotation) is the most frequent cause of intoeing in school-aged children. Femoral anteversion is defined by the angle of the femoral neck in relation to the femoral shaft in the coronal plane, whereas the degree of anteversion is greatest in infancy and gradually decreases towards skeletal maturity in most children. In about $15 \%$ of all children increased femoral anteversion persists into adulthood. In cases of excessive anteversion gait problems, hip and/or knee pain are common. Derotational osteotomy of the femur is an established treatment for the condition. However, there is a lack of knowledge and clear evidence when to perform surgery and how this affects function and pain in these patients. The current paper is not based on a complete literature review and, therefore, does not fulfill the criteria of a review article. However, the article is based on the authors' in-depth knowledge and a rapid review of the literature, and it can be defined as a scholarly article providing a perspective on the condition.
\end{abstract}

Keywords: children, adolescents, femur, acneversion, diagnosis, treatment, derotation osteotomy

\section{INTRODUCTION}

Gait problems with hip and knee pain due to increased femoral anteversion are frequent problems in children and adolescents. Derotational osteotomy (DRO) is an established treatment for adolescents with this condition. Rotational problems of the lower extremities affect a vast number of infants and children [1]. Increased femoral anteversion (inward rotation) is the most frequent cause of intoeing in school-aged children [2-4]. Femoral anteversion is defined by the angle of the femoral neck in relation to the femoral shaft in the coronal plane, whereas the degree of anteversion is greatest in infancy and gradually decreases towards skeletal maturity.

Fabry et al studied 1,148 hips and found that the anteversion angle decreased from 40 degrees at birth to 16 degrees at age of 16, and Svenningsen et al (1989) studied 30 children and found that all but 5 patients resolved spontaneously, which means the deformity is self-correcting in most children. However, these studies indicate that in about $15 \%$ of the children increased anteversion persists into adolescence, which would correspond to a yearly incidence of 7,000 8,000 children in Norway. In the city of Oslo, $11 \%$ of all referrals from family doctors to our specialized pediatric orthopedic service apply to intoeing children [5]. Persistent increased femoral anteversion after the age of 8 years has shown gait disturbances and a variety of clinical symptoms such as hip and knee pain during running and sport activities, including anterior knee pain, patellofemoral instability and a life-long burden for these patients [6]. These children are mainly referred to a pediatric orthopedic surgeon because of intoeing gait, and treatment has so far been limited to surgical correction for symptomatic cases of excessive anteversion [1], depending on the severity of symptoms [7]. There was a former belief that increased femoral anteversion might cause hip or knee osteoarthritis and the deformity was therefore corrected at a younger age as prophylactic intervention $[8,9]$. Some studies support the belief that increased femoral anteversion predisposes to osteoarthritis of the hip [9-12], whereas others do not support this hypothesis [13-15].

The decision whether to operate or not should therefore be based on the symptomatology and not on possible long-term consequences of the condition. Surgery in terms of derotational osteotomy is usually done consecutively in both femora with a time interval of 6 months, with each side requiring 3 months of bony healing with a corresponding time on crutches and 3 months of training to regain full function, resulting in a treatment time of 12 months for both femora. Furthermore, complication rates are described to be up to $15 \%$ [1]. Further surgery might be necessary to remove the implants. Considering the number of surgeries required and the time of treatment, surgical treatment is

Horn J. Treatment of idiopathic increased femoral anteversion in children and adolescents- a perspective. Genij Ortopedii, 2021, vol. 27, no 4, pp. 450-452. DOI 10.18019/1028-4427-2021-27-4-450-452 
a large burden for the patients and their caretakers, and an economic burden for the health care system.

The indication for surgical treatment remains controversial, and the benefit of such surgery remains unclear. There is only one study which has reported on patient-reported outcomes (PROs) after derotational osteotomy [16]. Hence, the efficacy of DRO is poorly documented. To my knowledge no study has been performed which has examined targeted physical therapy (TPT) in these patients.

Increased femoral anteversion is a bony deformity, and because of that there is a general belief that physical therapy is ineffective. On the other hand, it might be assumed that rather muscular compensation mechanisms cause pain and muscle tiredness in these patients than the bony deformity itself, and that targeted physical therapy nonetheless might be an effective treatment in order to reduce pain and improve function. Physical therapy has been shown effective in numerous high-quality clinical trials when compared with surgical interventions for orthopedic shoulder-, hip- and knee conditions [19-23]. There is a reason to believe that physical therapy also might be effective in some patients with idiopathic increased femoral anteversion. Furthermore, the fact that a significant percentage of adolescents suffer from functional hip and knee pain without the existence of any bony deformity $[17,18]$, a clear indication for surgery beyond doubt might be difficult to achieve.
Obviously, there is a lack of knowledge and a lack of clear evidence on when to perform derotational osteotomy and there are no reports in literature on the efficacy of conservative treatment in terms of targeted physical therapy. A significant number of patients might be operated unnecessarily while the efficacy of targeted physical activity/therapy remains unexplored in patients with impaired function and pain due to increased femoral anteversion. Furthermore, no study has been performed analyzing differences in selfreported (child) and proxy-reported (parents) quality of life measures in conjunction with idiopathic increased femoral anteversion. In many patients intoeing gait because of increased femoral anteversion might be greater concern of the parents than for the child itself.

Current clinical practice should be challenged by further clinical research. Further research is required to analyze the efficacy of surgical treatment and other treatment options such as targeted physical therapy, and all aspects that make these children/families seeking help by the health care providers for the condition. The results from such research would allow us to gain knowledge on how to carefully select patients that would benefit from surgery and avoid surgery when it is not needed, and improve quality of care for this patient group. New knowledge on the efficacy of these interventions in children and adolescence is critical for making both individual patient- as well as populationbased decisions.

\section{CONCLUSIONS}

Increased femoral anteversion accompanied by gait problems, hip and/or knee pain is a common problem in children and adolescents. In most cases increased anteversion is moderate and does not require treatment. However, femoral anteversion might be excessive and cause problems in these patients. On the other hand, hip and/or knee pain in this age group are common phenomena, also when no bony deformity is present. Deroational osteotomy is an etablished treatment for the condition, but its efficacy is not well documented both in terms of function and quality of life. Since increased femoral anteversion is a bony deformity, there is a general belief that physical therapy is ineffective. However, there might be patients with the condition that could benefit from a targeted physical therapy approach. Furthermore, the decision whether to operate or not might partially be influenced by the parents/caretakers perception of the condition, being concerned by the child's gait, including its cosmetic appearance, and the possible consequences of gait deviations for the child's performance in sports.
The decision whether to operate or not should be based on the symptomatology, which should include symptoms during sports as well as daily activities. Symptoms related to increased anteversion might be more pronounced during running and sports. The child's perspective should be considered besides the parents/caretakers perception. Until further research on the condition is available, only selected patients should be treated surgically with derotational osteotomy. At our institution we would not operate children and adolescents with increased femoral anteversion before the age 10 years in order to await natural development with spontaneous correction in most children.

Surgical treatment might be offered in patients older than 10 years of age with unilateral or bilateral idiopathic increased femoral anteversion defined by: intoeing gait, hip and/or knee pain, excessive internal rotation in the hip and $<15$ degrees external rotation, and an anteversion angle of $>30-40$ degrees based on CT measurements. 


\section{REFERENCES}

1. Staheli L.T. Torsion - treatment indications. Clin. Orthop. Relat. Res., 1989, no. 247, pp. 61-66.

2. Lincoln T.L., Suen P.W. Common rotational variations in children. J. Am. Acad. Orthop. Surg., 2003, vol. 11, no. 5, pp. 312- 320. DOI: 10.5435/00124635200309000-00004.

3. Staheli L.T. Rotational problems of the lower extremities. Orthop. Clin. North Am., 1987, vol. 18, no. 4, pp. 503-512.

4. Fabry G., Cheng L.X., Molenaers G. Normal and abnormal torsional development in children. Clin. Orthop. Relat. Res., 1994, no. 302, pp. 22-26.

5. Horn J. Referral patterns to the pediatric orthopedic service in Oslo - implications for education in primary health care. Oslo (Norway), Ortopedisk Høstmøte, 2018.

6. Nelitz M. Femoral Derotational Osteotomies. Curr. Rev. Musculoskelet. Med., 2018, vol. 11, no. 2, pp. 272-279. DOI: 10.1007/s12178-018-9483-2.

7. Sonoda S., Okada Y., Mori H., Uemura F., Sugai K., Hajime M., Tanaka K., Kurozumi A., Narisawa M., Torimoto K., Tanaka Y. Association Between Diabetic Microangiopathies and Glycemic Variability Assessed by Continuous Glucose Monitoring. J. UOEH, 2018, vol. 40, no. 1, pp. 11-18. DOI: 10.7888/ juoeh.40.11. PMID: 29553071.

8. Halpern A.A., Tanner J., Rinsky L. Does persistent fetal femoral anteversion contribute to osteoarthritis?: a preliminary report. Clin. Orthop. Relat. Res., 1979, no. 145, pp. 213-216.

9. Terjesen T., Benum P., Anda S., Svenningsen S. Increased femoral anteversion and osteoarthritis of the hip joint. Acta Orthop. Scand., 1982, vol. 53, no. 4. pp. 571-575. DOI: 10.3109/17453678208992260.

10. Giunti A., Moroni A., Olmi R., Rimondi E., Soldati D., Vicenzi G. The importance of the angle of anteversion in the development of arthritis of the hip. Ital. J. Orthop. Traumatol., 1985, vol. 11, no. 1, pp. 23-27.

11. Reikerås O., Bjerkreim I., Kolbenstvedt A. Anteversion of the acetabulum and femoral neck in normals and in patients with osteoarthritis of the hip. Acta Orthop. Scand., 1983, vol. 54, no. 1, pp. 18-23. DOI: 10.3109/17453678308992864.

12. ReikeråsO.,HøisethA.Femoralneckanglesinosteoarthritisofthehip.ActaOrthop.Scand.,1982,vol.53,no.5,pp.781-784.DOI: 10.3109/17453678208992292.

13. Hubbard D.D., Staheli L.T., Chew D.E., Mosca V.S. Medial femoral torsion and osteoarthritis. J. Pediatr. Orthop., 1988, vol. 8, no. 5, pp. 540-542. DOI: 10.1097/01241398-198809000-00008.

14. Kitaoka H.B., Weiner D.S., Cook A.J., Hoyt W.A. Jr, Askew M.J. Relationship between femoral anteversion and osteoarthritis of the hip. J. Pediatr. Orthop., 1989, vol. 9, no. 4, pp. 396-404.

15. Swanson A.B., Greene P.W. Jr., Allis H.D. Rotational deformities of the lower extremity in children and their clinical significance. Clin. Orthop. Relat. Res., 1963, vol. 27, pp. 157-175.

16. Stambough J.B., Davis L., Szymanski D.A., Smith J.C., Schoenecker P.L., Gordon J.E. Knee Pain and Activity Outcomes After Femoral Derotation Osteotomy for Excessive Femoral Anteversion. J. Pediatr. Orthop., 2018, vol. 38, no. 10, pp. 503-509. DOI: 10.1097/BPO.0000000000000874.

17. Roth-Isigkeit A., Thyen U., Stöven H., Schwarzenberger J., Schmucker P. Pain among children and adolescents: restrictions in daily living and triggering factors. Pediatrics, 2005, vol. 115, no. 2, pp. e152-e162. DOI: 10.1542/peds.2004-0682.

18. Spahn G., Schiele R., Langlotz A., Jung R. Prävalenz funktioneller Beschwerden des Rückens und der Hüft- und Kniegelenke bei Adoleszenten. Ergebnisse einer Querschnittuntersuchung [Prevalence of functional pain of the back, the hip and the knee in adolescents. Results of a cross-sectional study]. Dtsch. Med. Wochenschr., 2004. Vol. 129, No 43. P. 2285-2290. (in German) DOI: 10.1055/s-2004-835256.

19. Grindem H., Eitzen I., Engebretsen L., Snyder-Mackler L., Risberg M.A. Nonsurgical or Surgical Treatment of ACL Injuries: Knee Function, Sports Participation, and Knee Reinjury: The Delaware-Oslo ACL Cohort Study. J. Bone Joint Surg. Am., 2014, vol. 96, no. 15, pp. 1233-1241. DOI: 10.2106/ JBJS.M.01054.

20. Katz J.N., Brophy R.H., Chaisson C.E., de Chaves L., Cole B.J., Dahm D.L., Donnell-Fink L.A., Guermazi A., Haas A.K., Jones M.H., Levy B.A., Mandl L.A., Martin S.D., Marx R.G., Miniaci A., Matava M.J., Palmisano J., Reinke E.K., Richardson B.E., Rome B.N., Safran-Norton C.E., Skoniecki D.J., Solomon D.H., Smith M.V., Spindler K.P., Stuart M.J., Wright J., Wright R.W., Losina E. Surgery versus physical therapy for a meniscal tear and osteoarthritis. N. Engl. J. Med., 2013, vol. 368, no. 18, pp. 1675-1684. DOI: 10.1056/NEJMoa1301408.

21. Kise N.J., Risberg M.A., Stensrud S., Ranstam J., Engebretsen L., Roos E.M. Exercise therapy versus arthroscopic partial meniscectomy for degenerative meniscal tear in middle aged patients: randomised controlled trial with two year follow-up. BMJ, 2016, vol. 354, pp. i3740. DOI: 10.1136/bmj.i3740.

22. Haahr J.P., Andersen J.H. Exercises may be as efficient as subacromial decompression in patients with subacromial stage II impingement: 4-8-years' followup in a prospective, randomized study. Scand. J. Rheumatol., 2006, vol. 35, no. 3, pp. 224-228. DOI: 10.1080/03009740600556167.

23. Kemp J.L., Mosler A.B., Hart H., Bizzini M., Chang S., Scholes M.J., Semciw A.I., Crossley K.M. Improving function in people with hip-related pain: a systematic review and meta-analysis of physiotherapist-led interventions for hip-related pain. Br. J. Sports Med., 2020, vol. 54, no. 23, pp. 1382-1394. DOI: 10.1136/bjsports-2019-101690.

24. Reimer L.C.U., Jakobsen S.S., Mortensen L., Dalgas U., Jacobsen J.S., Soballe K., Bere T., Madsen J.E., Nordsletten L., Risberg M.A., Mechlenburg I. Efficacy of periacetabular osteotomy followed by progressive resistance training compared to progressive resistance training as non-surgical treatment in patients with hip dysplasia (PreserveHip) - a protocol for a randomised controlled trial. BMJ Open, 2019, vol. 9, no. 12, pp. e032782. DOI: 10.1136/ bmjopen-2019-032782.

25. Thorborg K., Hölmich P., Christensen R., Petersen J., Roos E.M. The Copenhagen Hip and Groin Outcome Score (HAGOS): development and validation according to the COSMIN checklist. Br. J. Sports Med., 2011, vol. 45, no. 6, pp. 478-491. DOI: 10.1136/bjsm.2010.080937.

26. Herngren B., Stenmarker M., Enskär K. Barnhöft: a hip specific 6-item questionnaire for children. J. Patient Rep. Outcomes, 2017 , vol. 1, no. 1, pp. 16. DOI: 10.1186/s41687-017-0024-3.

27. Jones C.J., Rikli R.E., Beam W.C. A 30-s chair-stand test as a measure of lower body strength in community-residing older adults. Res. Q Exerc. Sport, 1999, vol. 70, no. 2, pp. 113-119. DOI: 10.1080/02701367.1999.10608028.

28. Tveter A.T., Dagfinrud H., Moseng T., Holm I. Health-related physical fitness measures: reference values and reference equations for use in clinical practice. Arch. Phys. Med. Rehabil., 2014, vol. 95, no. 7, pp. 1366-1373. DOI: 10.1016/j.apmr.2014.02.016.

29. Tveter A.T., Dagfinrud H., Moseng T., Holm I. Measuring health-related physical fitness in physiotherapy practice: reliability, validity, and feasibility of clinical field tests and a patient-reported measure. J. Orthop. Sports Phys. Ther., 2014, vol. 44, no. 3, pp. 206-216. DOI: 10.2519/jospt.2014.5042.

30. Noyes F.R., Barber S.D., Mangine R.E. Abnormal lower limb symmetry determined by function hop tests after anterior cruciate ligament rupture. Am. J. Sports Med., 1991, vol. 19, no. 5, pp. 513-518. DOI: 10.1177/036354659101900518.

31. Barber S.D., Noyes F.R., Mangine R.E., McCloskey J.W., Hartman W. Quantitative assessment of functional limitations in normal and anterior cruciate ligament-deficient knees. Clin. Orthop. Relat. Res., 1990, no. 255, pp. 204-214.

32. Muka T., Glisic M., Milic J., Verhoog S., Bohlius J., Bramer W., Chowdhury R., Franco O.H. A 24-step guide on how to design, conduct, and successfully publish a systematic review and meta-analysis in medical research. Eur. J. Epidemiol., 2020, vol. 35, no. 1, pp. 49-60. DOI: 10.1007/s10654-019-00576-5.

33. McCoy C.E. Understanding the Intention-to-treat Principle in Randomized Controlled Trials. West. J. Emerg. Med., 2017, vol. 18, no. 6, pp. 1075-1078. DOI: 10.5811 /westjem.2017.8.35985.

Received: 7.07.2021

Information about the author:

Joachim Horn,

University of Oslo, Norway,

Oslo University Hospital, Oslo, Norway,

Email: jhorn@ous-hf.no 